\title{
PENGEMBANGAN PRODUK PRALINE APEL UNTUK MENDUKUNG PROGRAM ONE VILLAGE ONE PRODUCT DI KECAMATAN BUMIAJI, BATU
}

\author{
The Apple Praline Product Development to Support \\ One Village One Product Program at Bumiaji District, Batu
}

\author{
Dhita Morita Ikasari, Rizky Luthfian Ramadhan Silalahi, Ika Atsari Dewi, \\ Miftakhurrizal Kurniawan, Endah Rahayu Lestari, Wendra Gandhatyasri Rohmah* \\ Jurusan Teknologi Industri Pertanian - Fakultas Teknologi Pertanian - Universitas Brawijaya \\ Jalan Veteran, Malang 65145 \\ *Penulis Korespondensi: email wendrarohmah@ub.ac.id
}

Disubmit: 4 Mei 2017 Direvisi: 28 Januari 2019 Diterima: 15 Maret 2019

\begin{abstract}
ABSTRAK
Desa Bumiaji merupakan salah satu daerah di Kota Batu yang menghasilkan buah apel dan sangat potensial untuk dikembangkan konsep One Village One Product (OVOP). OVOP merupakan suatu pendekatan pengembangan potensi daerah di satu wilayah untuk menghasilkan produk yang mampu bersaing di pasar global, dengan tetap memiliki ciri khas keunikan karakteristik dari daerah tersebut. Produk yang dihasilkan adalah produk yang memanfaatkan sumber daya lokal. Oleh karena itu, Koperasi Usaha Bersama (KUB) Bumiaji ingin mengembangkan produk praline apel sebagai upaya pengembangan potensi Desa Bumiaji yang sesuai dengan konsep OVOP. Tujuan penelitian ini adalah untuk mendapatkan informasi kebutuhan dan keinginan konsumen terhadap produk praline apel yang akan dikembangkan oleh KUB Bumiaji. Metode penelitian yang digunakan dalam penelitian ini adalah Quality Function Deployment (QFD). Hasil penelitian menunjukkan bahwa atribut produk yang paling diinginkan oleh konsumen terhadap produk praline apel adalah keamanan dan jaminan halal produk praline apel
\end{abstract}

Kata kunci: Apel; OVOP; Pengembangan Produk; Praline; QFD

\begin{abstract}
Bumiaji Village is an area in Batu which produces apples and has high potential for developing concept of One Village One Product (OVOP). OVOP is a potential approach for developing area in aregion to produce a product that can compete in the global market, while still having a unique characteristic of the area. The product of this program is a product that utilizes local resources. Therefore, Koperasi Usaha Bersama (KUB) Bumiaji intends to develop the apple praline product as the potential development for Bumiaji Village that accordance with the concept of OVOP. The purpose of this study is to obtain information about what the consumer desires and needs related to the apple praline product that will be developed by KUB Bumiaji. The method used in this research is Quality Function Deployment (QFD). The results show that the most desirable product attributes by the consumers about the apple praline product are safety and halal product guarantee of the apple praline
\end{abstract}

Keywords: Apple; OVOP; Praline; Product Development; QFD 
Jurnal Teknologi Pertanian Vol. 20 No. 1 [April 2019] 1-10

Pengembangan Produk Praline Apel [Rohmah dkk]

\section{PENDAHULUAN}

One Village One Product (OVOP) merupakan suatu pendekatan pengembangan potensi daerah di satu wilayah untuk menghasilkan produk yang mampu bersaing di pasar global, dengan tetap memiliki ciri khas keunikan karakteristik dari daerah tersebut. Produk yang dihasilkan adalah produk yang memanfaatkan sumber daya lokal, baik sumber daya alam, maupun sumber daya manusia (Direktorat Jenderal Industri Kecil dan Menengah Kementrian Perindustrian Republik Indonesia, 2011). Desa Bumiaji merupakan salah satu daerah di Kota Batu yang sangat potensial untuk dikembangkan konsep OVOP. Komoditas unggulan yang dihasilkan desa tersebut adalah buah apel.

Dalam rangka memfasilitasi UMKM milik warga, dibentuklah Koperasi Usaha Bersama (KUB) Desa Bumiaji. UMKM tersebut memproduksi berbagai macam produk olahan apel diantaranya adalah keripik apel, jenang apel, dodol apel, dan sari apel. Seiring dengan berjalannya waktu, anggota KUB Bumiaji berkeinginan untuk memiliki produk bersama dengan cara memproduksi produk olahan apel berlabel KUB Bumiaji (bukan dengan label masing-masing UMKM). Salah satu produk olahan apel yang ingin dikembangkan sebagai produk bersama adalah praline apel.

Praline adalah jenis coklat yang ditambahkan bahan pengisi (filling) dengan berbagai macam bahan pengisi misalnya kacang-kacangan atau buah-buahan segar (Moeljaningsih, 2011). Selain itu, coklat praline juga lebih menonjolkan bentuk yang menarik dan isi yang beraneka ragam dengan cara pembuatan yang sama dengan permen coklat, yakni dengan melelehkan coklat dan dicetak dengan menggunakan alat pencetak (Rangkuti, 2013).

Produk praline apel dipilih oleh KUB Bumiaji karena mereka menganggap produk yang berbahan dasar cokelat sangat diminati oleh konsumen. Selain itu, praline apel dinilai memiliki nilai ekonomis yang tinggi sehingga diharapkan dapat mendongkrak keuntungan KUB Bumiaji. Pada pengembangan produk, produk harus dipandang sebagai pemecahan masalah bagi konsumen, dimana jika seorang konsumen membeli sebuah produk, konsumen percaya bahwa suatu produk dapat memenuhi kebutuhannya. Jika kebutuhan konsumen sudah terpenuhi, di- harapkan timbul kepuasan sehingga di masa yang akan datang akan melakukan pembelian berikutnya terhadap produk yang sama.

Metode yang dapat digunakan untuk mengetahui keinginan dan kebutuhan konsumen terhadap kualitas produk adalah metode QFD (Quality Function Deployment). Metode QFD lebih fokus dalam pengembangan dan perbaikan dari keinginan dan kebutuhan konsumen dengan melakukan perbandingan terhadap kompetitor lain (Suryaningrat et al., 2010). Metode QFD mencakup satu atau lebih matriks yang dikenal sebagai "tabel kualitas. Matriks pertama adalah "House of Quality" (HoQ). Hal ini menunjukkan kebutuhan pelanggan (Voice of Customer) di sisi kiri, dan respon teknis untuk memenuhi kebutuhan di sisi atas (Jaiswal, 2012). Tujuan penelitian ini adalah untuk mendapatkan informasi prioritas kebutuhan dan keinginan konsumen terhadap produk praline apel KUB Bumiaji.

\section{METODE}

Penelitian dilaksanakan di Kota Batu, Jawa Timur, dengan objek penelitian yaitu KUB. Analisis data dalam penelitian ini dibatasi hanya sampai dengan penyusunan matriks House of Quality (HoQ). Tahapan penelitian dapat dilihat pada Gambar 1.

Penentuan responden pada penelitian ini menggunakan teknik purposive sampling yang merupakan salah satu teknik pengambilan sampel nonprobability sampling. Purposive sampling adalah teknik penentuan sampel dengan pertimbangan tertentu. Hal ini dilakukan dengan cara mengambil subjek bukan didasarkan atas strata, random atau daerah tetapi didasarkan atas adanya tujuan tertentu (Sugiyono, 2012).

Total responden yang digunakan dalam penelitian ini adalah 100 responden. Penentuan sampel minimal dilakukan setelah mengetahui bahwa kuesioner telah valid dan reliabel. Besarnya sampel minimum untuk penelitian deskriptif adalah sebanyak 100 responden (Asnawi dan Masyhuri, 2011).

Kuesioner disusun berdasarkan persyaratan pelanggan ('What' attributes) yang terdiri dari 2 jenis yaitu persyaratan primer dan persyaratan sekunder. Persyaratan pelanggan (primer dan sekunder) yang kemudian disebut dengan atribut pelanggan (whats) dapat dilihat pada Tabel 1. Analisis data yang digunakan adalah metode Quality Function Deployment (QFD). 
Adapun tahapan metode QFD (menyusun matriks House of Quality) adalah (Anggraeni et al., 2013):

1. Pembuatan spesifikasi teknik yang terdiri dari atribut, matriks, spesifikasi teknis, satuan dan kriteria

2. Menilai kekuatan hubungan antara atribut dengan spesifikasi teknik

3. Mengembangkan matriks perencanaan

4. Mengembangkan korelasi antara spesifikasi teknik yang satu dengan yang lain

5. Menentukan urutan tingkat kepentingan daya saing dan target untuk persyaratan teknis

\section{HASIL DAN PEMBAHASAN}

\section{Gambaran Umum Responden}

Penelitian ini melibatkan responden yang pernah mengkonsumsi produk praline. Profil responden meliputi jenis kelamin, usia, pekerjaan, dan pendapatan per bulan.

\section{Hasil Uji Validitas dan Reliabilitas}

Data yang telah didapatkan melalui penyebaran kuesioner diuji validitas dan reliabilitasnya. Uji validitas ialah suatu langkah pengujian yang dilakukan terhadap isi (konten) dari suatu instrumen, dengan tujuan untuk mengukur ketepatan instrumen (kuesioner) yang digunakan dalam suatu penelitian (Putra et al., 2014).

Hasil uji validitas dapat dilihat pada Tabel 2. Berdasarkan Tabel 2, diketahui bahwa seluruh atribut dari masing-masing variabel dinyatakan valid. Hal tersebut dapat diketahui dari nilai $r$ hitung $>r$ tabel, dimana nilai $r$ tabel yaitu 0.1966. Alat ukur penelitian yang baik adalah alat ukur yang mampu memenuhi aspek validitas. Validitas merupakan kemampuan sebuah tes atau instrumen untuk memberikan hasil yang benar. Menurut Kosasih et al. (2013), jika $r$ hitung $>r$ tabel maka data hasil kuisioner dianggap valid/ tepat untuk mengukur variabel penelitian.

Langkah selanjutnya setelah pengujian validitas adalah pengujian reliabilitas, hasil uji reliabilitas dapat dilihat pada Tabel 3. Berdasarkan Tabel 3, seluruh variabel penelitian memiliki nilai Cronbach's alpha $>0.70$ yang berarti variabel tersebut reliabel. Reliabilitas merupakan ukuran suatu kesetabilan dan konsistensi responden dalam menjawab pertanyaaan atau variabel dalam bentuk kuesioner. Nilai reliabilitas suatu konstruk variabel harus lebih dari 0.7 agar tes konsisten secara internal (Ghazali, 2016).

\section{Atribut Prioritas Praline Apel Bagi Konsumen}

Produk memiliki beberapa atribut yang menjadi faktor bagi konsumen untuk memutuskan akan membeli produk yang mana dari sekian banyak pilihan. Penilaian konsumen terhadap tingkat kepentingan masing-masing atribut praline apel secara ringkas dapat dilihat pada Tabel 4.

Tingkat keamanan pangan dan jaminan halal merupakan hal utama yang dicari oleh konsumen. Banyak konsumen yang lebih mengutamakan untuk mendapatkan tingkat keamanan pangan terpecaya dan jaminan halalnya. Sertifikat halal adalah fatwa tertulis Majelis Ulama Indonesia (MUI) yang menyatakan kehalalan suatu produk pangan, obatobatan, dan kosmetik. Sertifikat halal akan mempermudah proses pemasaran makanan atau minuman pada konsumen mayoritas di Indonesia. Kesinambungan proses produksi halal dijamin oleh produsen dengan cara menerapkan sistem jaminan halal (Aqimudin dan Kusmagi, 2010).

\section{Pengukuran Kepuasan Konsumen}

Pengukuran kepuasan dilakukan untuk mengetahui tingkat kepuasan konsumen terhadap produk praline, sehingga dapat dijadikan pertimbangan dalam pengembangan kualitas produk. Hasil pengukuran kepuasan konsumen dapat dilihat pada Tabel 5. Berdasarkan nilai harapan dan nilai kinerja diketahui bahwa nilai persepsi konsumen lebih kecil dari nilai harapan konsumen dengan nilai gap negatif. Kondisi ini menunjukkan bahwa produk praline memerlukan perbaikan atau pengembangan produk untuk dapat memenuhi kebutuhan konsumen.

Gap terbesar terletak pada atribut keamanan dan jaminan halal praline (X12). Atribut dengan gap terbesar tersebut memerlukan perhatian lebih besar dalam hal perbaikan dan pengembangan produk. Atribut dengan selisih negatif terkecil terletak pada atribut kesesuaian bahan kemasan yang digunakan (X11) artinya atribut ini sedikit mendekati tingkat kepuasan konsumen. Gap negatif yang semakin besar antara kenyataan dan harapan berarti atribut tersebut memiliki prioritas terbesar untuk diperbaiki (Diana, 2015). 
Analisis Quality Function Deployment (QFD) Adapun langkah-langkah analisis QFD adalah sebagai berikut:

1. Menentukan derajat kepentingan tiap atribut Derajat kepentingan digunakan untuk memposisikan setiap keinginan konsumen dalam bentuk data kualitatif yang bertujuan untuk memprioritaskan keinginan konsumen. Adapun hasil perhitungan dapat dilihat dalam Tabel 6.

2. Menentukan kinerja atribut produk

Kinerja atribut produk perusahaan dari sudut pandang konsumen digunakan untuk menentukan besarnya nilai target oleh pihak manajemen. Hasil perhitungan nilai kinerja atribut produk dapat

Tabel 1. Atribut pelanggan (Whats)

\begin{tabular}{lll}
\hline No. & Persyaratan Primer & Persyaratan Sekunder \\
\hline 1. & Performance & Rasa, tekstur, aroma, warna, dan harga \\
2. & Features & Bentuk produk \\
3. & Reliability & Manfaat yang bisa diambil dari produk \\
4. & Conformance to specification & Tanpa bahan pengawet \\
5. & Durability & Masa kedaluwarsa produk \\
6. & Aesthetics & Warna kemasan primer dan sekunder, bahan kemasan, \\
& & bentuk kemasan, warna tulisan/huruf pada kemasan, \\
7. & Perceived quality & Kejelasan label halal, izin Depkes dan P-IRT pada kemasan \\
\hline
\end{tabular}

Tabel 2. Hasil uji validitas instrumen penelitian

\section{Koefisien korelasi ( $r$ hitung)}

\begin{tabular}{|c|c|c|c|c|c|c|}
\hline Variabel & Atribut & 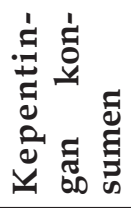 & 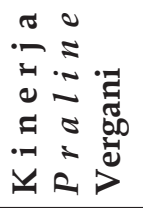 & 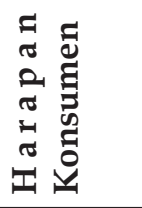 & $\begin{array}{c}\text { Nilai } \\
\text { r tabel }\end{array}$ & Keterangan \\
\hline \multirow[t]{5}{*}{ Kinerja } & $\mathrm{X} 1$ & 0.479 & 0.625 & 0.572 & 0.1966 & Valid \\
\hline & $\mathrm{X} 2$ & 0.565 & 0.651 & 0.712 & 0.1966 & Valid \\
\hline & $\mathrm{X} 3$ & 0.489 & 0.724 & 0.599 & 0.1966 & Valid \\
\hline & $X 4$ & 0.630 & 0.622 & 0.602 & 0.1966 & Valid \\
\hline & X5 & 0.522 & 0.687 & 0.462 & 0.1966 & Valid \\
\hline Fitur & $X 6$ & 0.497 & 0.692 & 0.704 & 0.1966 & Valid \\
\hline Keandalan & $X 7$ & 0.440 & 0.555 & 0.512 & 0.1966 & Valid \\
\hline Kesesuaian spesifikasi & $\mathrm{X} 8$ & 0.286 & 0.601 & 0.471 & 0.1966 & Valid \\
\hline Daya tahan & X9 & 0.406 & 0.646 & 0.412 & 0.1966 & Valid \\
\hline \multirow[t]{2}{*}{ Estetika } & $\mathrm{X} 10$ & 0.508 & 0.669 & 0.581 & 0.1966 & Valid \\
\hline & $\mathrm{X} 11$ & 0.489 & 0.590 & 0.659 & 0.1966 & Valid \\
\hline Persepsi kualitas & $\mathrm{X} 12$ & 0.332 & 0.519 & 0.595 & 0.1966 & Valid \\
\hline
\end{tabular}

Tabel 3. Hasil uji reliabilitas

Variabel

Kepentingan konsumen
Kinerja praline vergani
Harapan konsumen

Nilai Cronbach's Alpha
Syarat reliabilitas Keterangan

$\begin{array}{lll}0.775 & >0.70 & \text { Reliabel } \\ 0.850 & >0.70 & \text { Reliabel } \\ 0.808 & >0.70 & \text { Reliabel }\end{array}$


diketahui bahwa nilai kinerja atribut terendah terdapat pada atribut keamanan dan jaminan halal praline (X12). Nilai terendah menunjukkan bahwa atribut tersebut diprioritaskan untuk diperbaiki.

3. Menentukan nilai target dari setiap atribut produk

Nilai posisi pasar yang dituju (Market Position)/nilai target diperoleh dari perbandingan kepuasan pelanggan terhadap produk perusahaan dengan produk pesaing dan dengan harapan konsumen. Nilai yang dipilih adalah nilai yang lebih unggul atau sama. Nilai target masingmasing atribut produk praline apel dapat dilihat pada Tabel 7.

4. Menentukan rasio perbaikan

Atribut produk yang mempunyai nilai kurang dari 1 adalah tekstur praline ideal (X2) dan daya simpan praline lama (X9). Dengan demikian, kedua atribut tersebut tidak memerlukan perbaikan. Atribut keamanan dan jaminan halal praline memiliki nilai rasio perbaikan 1.71 yang berarti atribut tersebut membutuhkan perbaikan sebesar $71 \%$. Menurut Devani dan Kartikasari (2012), semakin besar nilai improvement ratio maka semakin besar pula usaha perbaikan yang diperlukan.

5. Menentukan sales point

Penelitian ini menggunakan pertimbangan nilai kinerja pesaing dan harapan konsumen. Berdasarkan data nilai sales point praline diketahui seluruh atribut produk praline dalam penelitian ini tidak memiliki sales point atau tidak ada titik penjualan. Hal tersebut diketahui dari sales point yang bernilai 1. Penentuan sales point bertujuan untuk memberi penilaian terhadap atribut mana yang perlu mendapat perbaikan dalam usaha meningkatkan kemampuan persaingan pada suatu produk (Zagloel dan Nurcahyo, 2013).

6. Menentukan bobot dari setiap atribut produk

Nilai bobot tertinggi terdapat pada atribut keamanan dan jaminan halal praline (X12). Nilai bobot terendah terdapat pada atribut tekstur praline ideal (X2). Menyediakan pangan halal dan aman adalah bisnis yang sangat prospektif, karena dengan label (sertifikasi) halal dapat mengundang pelanggan loyal yang bukan saja diminati oleh muslim tetapi juga masyarakat non muslim (Hidayat dan Siradj, 2015).

\section{Menentukan normalisasi bobot}

Prioritas pengembangan produk praline apel adalah atribut keamanan dan jaminan halal praline (X12), sehingga perlu adanya perbaikan dalam pembuatan praline supaya menghasilkan produk yang keaman dan kehalalannya dapat dipercaya oleh konsumen. Normalisasi merupakan parameter digunakan untuk menghindari duplikasi terhadap tabel dalam basis data dan juga merupakan proses mendekomposisikan sebuah tabel yang masih memiliki beberapa anomali atau ketidakwajaran sehingga menghasilkan tabel yang lebih sederhana dan struktur yang bagus. Hal ini untuk

Tabel 4. Faktor prioritas konsumen praline apel

\begin{tabular}{clcc}
\hline \multirow{2}{*}{ No } & \multirow{2}{*}{ Kebutuhan Konsumen } & \multicolumn{2}{c}{ Tingkat Kepentingan } \\
\cline { 2 - 4 } & & Rata-rata & Ranking \\
\hline 1 & Rasa praline enak (X1) & 4.54 & 2 \\
2 & Tekstur praline ideal (X2) & 4.06 & 10 \\
3 & Aroma praline khas (X3) & $3.96^{* *}$ & 12 \\
4 & Warna praline menarik (X4) & 4.04 & 11 \\
5 & Harga praline sesuai kualitas (X5) & 4.44 & 3 \\
6 & Bentuk praline menarik (X6) & 4.07 & 9 \\
7 & Praline apel sebagai oleh-oleh (X7) & 4.1 & 7 \\
8 & Praline tanpa bahan pengawet (X8) & 4.35 & 5 \\
9 & Daya simpan Praline lama (X9) & 4.08 & 8 \\
10 & Bentuk dan desain kemasan praline menarik (X10) & 4.36 & 4 \\
11 & Kesesuaian bahan kemasan yang digunakan (X11) & 4.19 & 6 \\
12 & Keamanan dan jaminan Halal Praline (X12) & $4.8^{*}$ & 1 \\
\hline
\end{tabular}


menghilangkan kesulitan perhitungan dalam menentukan alternatif terbaik (Triyono, 2011).

8. Identifikasi karakter teknis

Kebutuhan teknis merupakan karakteristik desain yang menggambarkan kebutuhan pelanggan dalam desainer. Pada intinya, kebutuhan ini menjawab pertanyaan "bagaimana" cara perusahaan merespons "apa" yang menjadi ke- butuhan pelanggan. Terdapat 11 karakteristik teknis produksi praline apel yang dapat dilihat pada Tabel 8 .

9. Menentukan interaksi antara keinginan konsumen dengan karakteristik teknis

Hasil penilaian terhadap hubungan kebutuhan konsumen dengan karakteristik teknis produk praline dituangkan dalam matriks relationship yang dapat dilihat pada Gambar 2. Pada QFD selain hubungan antara kebutuhan konsumen

Tabel 5. Hasil Pengukuran Kepuasan Konsumen

\begin{tabular}{|c|c|c|c|c|c|c|}
\hline \multirow[b]{2}{*}{ No } & \multirow[b]{2}{*}{$\begin{array}{l}\text { Kebutuhan } \\
\text { Konsumen }\end{array}$} & \multicolumn{2}{|c|}{ Nilai Total } & \multicolumn{2}{|c|}{ Rata-rata } & \multirow[b]{2}{*}{$\begin{array}{c}\text { Selisih } \\
\text { (Gap) }\end{array}$} \\
\hline & & $\begin{array}{l}\text { Kinerja } \\
\text { Perusahaan } \\
\text { (P) }\end{array}$ & $\begin{array}{l}\text { Harapan } \\
\text { Konsumen } \\
\quad(\mathrm{H})\end{array}$ & $\begin{array}{l}\text { Kinerja } \\
\text { Perusahaan } \\
\quad \text { (P) }\end{array}$ & $\begin{array}{l}\text { Harapan } \\
\text { Konsumen } \\
\quad(\mathrm{H})\end{array}$ & \\
\hline & Kinerja & & & & & \\
\hline 1 & rasa praline enak (X1) & 418 & 457 & 4.18 & 4.57 & -0.39 \\
\hline 2 & tekstur praline ideal (X2) & 380 & 424 & 3.80 & 4.24 & -0.44 \\
\hline 3 & aroma praline khas (X3) & 368 & 408 & 3.68 & 4.08 & -0.40 \\
\hline 4 & $\begin{array}{l}\text { warna praline menarik } \\
(\mathrm{X} 4)\end{array}$ & 389 & 423 & 3.89 & 4.23 & -0.34 \\
\hline 5 & $\begin{array}{l}\text { harga praline sesuai } \\
\text { kualitas (X5) }\end{array}$ & 403 & 445 & 4.03 & 4.45 & -0.42 \\
\hline 6 & $\begin{array}{l}\text { Fitur } \\
\text { Bentuk praline menarik } \\
\text { (X6) }\end{array}$ & 388 & 413 & 3.88 & 4.13 & -0.25 \\
\hline 7 & $\begin{array}{l}\text { Keandalan } \\
\text { Praline apel sebagai } \\
\text { oleh-oleh (X7) }\end{array}$ & 388 & 415 & 3.88 & 4.15 & -0.27 \\
\hline 8 & $\begin{array}{l}\text { Kesesuaian Spesifikasi } \\
\text { Praline tanpa bahan } \\
\text { pengawet }(\mathrm{X} 8)\end{array}$ & 389 & 448 & 3.89 & 4.48 & -0.59 \\
\hline \multirow[t]{2}{*}{9} & $\begin{array}{l}\text { Daya tahan } \\
\text { Daya simpan Praline } \\
\text { lama (X9) }\end{array}$ & 408 & 417 & 4.08 & 4.17 & -0.09 \\
\hline & Estetika & & & & & \\
\hline 10 & $\begin{array}{l}\text { Bentuk dan desain ke- } \\
\text { masan praline menarik } \\
\text { (X10) }\end{array}$ & 421 & 447 & 4.21 & 4.47 & -0.26 \\
\hline 11 & $\begin{array}{l}\text { Kesesuaian bahan ke- } \\
\text { masan yang digunakan } \\
\text { (X11) }\end{array}$ & 428 & 429 & 4.28 & 4.9 & $-0.01^{* *}$ \\
\hline & Persepsi Kualitas & & & & & \\
\hline 12 & $\begin{array}{l}\text { Keamanan dan jami- } \\
\text { nan halal praline }(\mathrm{X} 12)\end{array}$ & 293 & 478 & 2.93 & 4.78 & $-1.85^{*}$ \\
\hline
\end{tabular}


Tabel 6. Derajat kepentingan

\begin{tabular}{clcc}
\hline No & Atribut & Total & Derajat Kepentingan \\
\hline 1 & Rasa praline enak (X1) & 454 & 4.54 \\
2 & Tekstur praline ideal (X2) & 406 & 4.06 \\
3 & Aroma praline khas (X3) & 396 & 3.96 \\
4 & Warna praline menarik (X4) & 404 & 4.04 \\
5 & Harga praline sesuai kualitas (X5) & 444 & 4.44 \\
6 & Bentuk praline menarik (X6) & 407 & 4.07 \\
7 & Praline apel sebagai oleh-oleh (X7) & 410 & 4.1 \\
8 & Praline tanpa bahan pengawet (X8) & 435 & 4.35 \\
9 & Daya simpan Praline lama (X9) & 408 & 4.08 \\
10 & Bentuk dan desain kemasan praline menarik (X10) & 436 & 4.36 \\
11 & Kesesuaian bahan kemasan yang digunakan (X11) & 419 & 4.19 \\
12 & Keamanan dan jaminan Halal Praline(X12) & 480 & $4.8^{* *}$ \\
\hline
\end{tabular}

Keterangan : ${ }^{* *}$ ) nilai tertinggi

Tabel 7. Nilai target masing-masing atribut

\begin{tabular}{clc}
\hline No & Atribut & Nilai Target \\
\hline 1 & Rasa praline enak (x1) & 5 \\
2 & Tekstur praline ideal (x2) & 3 \\
3 & Aroma praline khas (x3) & 4 \\
4 & Warna praline menarik (x4) & 5 \\
5 & Targa praline sesuai kualitas (x5) & 5 \\
6 & Bentuk praline menarik (x6) & 5 \\
7 & Praline apel sebagai oleh-oleh (X7) & 5 \\
8 & Praline tanpa bahan pengawet (X8) & 5 \\
9 & Daya simpan Praline lama (X9) & 4 \\
10 & Bentuk dan desain kemasan praline menarik (X10) & 5 \\
11 & Kesesuaian bahan kemasan yang digunakan (X11) & 5 \\
12 & Keamanan dan jaminan Halal Praline(X12) & 5 \\
\hline
\end{tabular}

Tabel 8. Karakteristik teknis praline apel

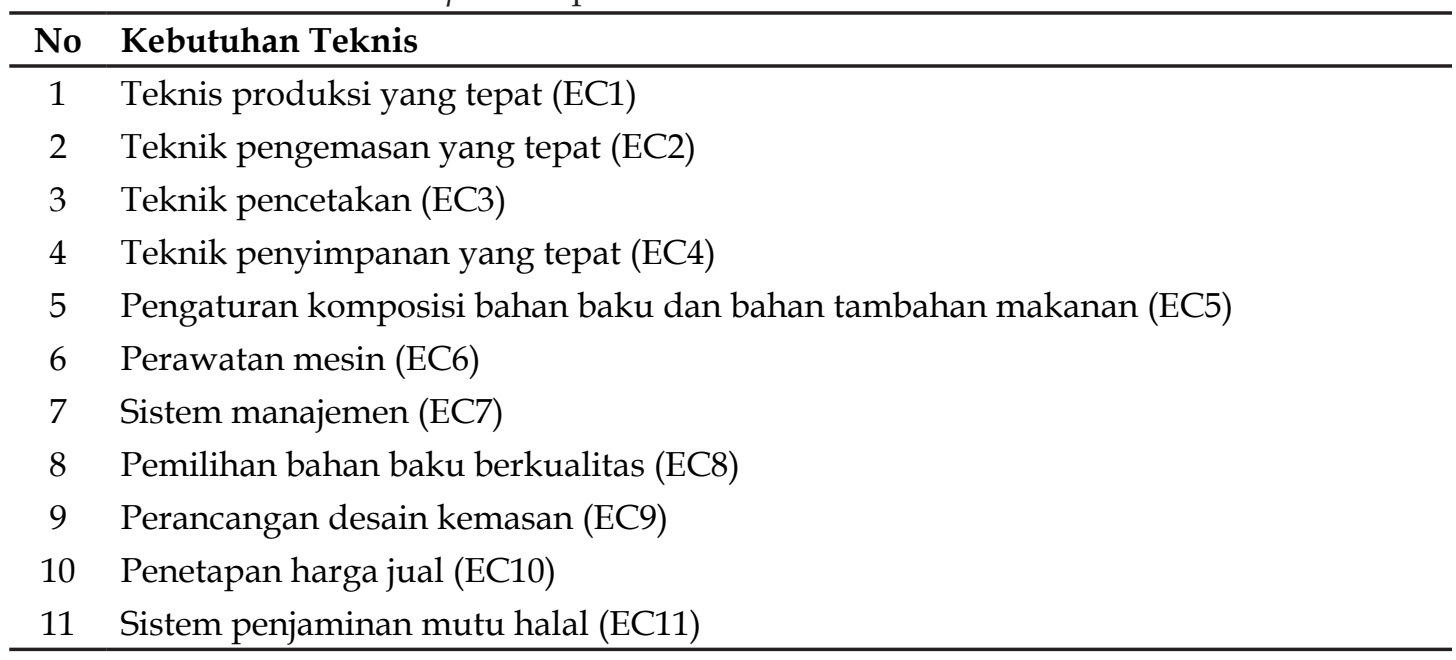


Jurnal Teknologi Pertanian Vol. 20 No. 1 [April 2019] 1-10

Pengembangan Produk Praline Apel [Rohmah dkk]

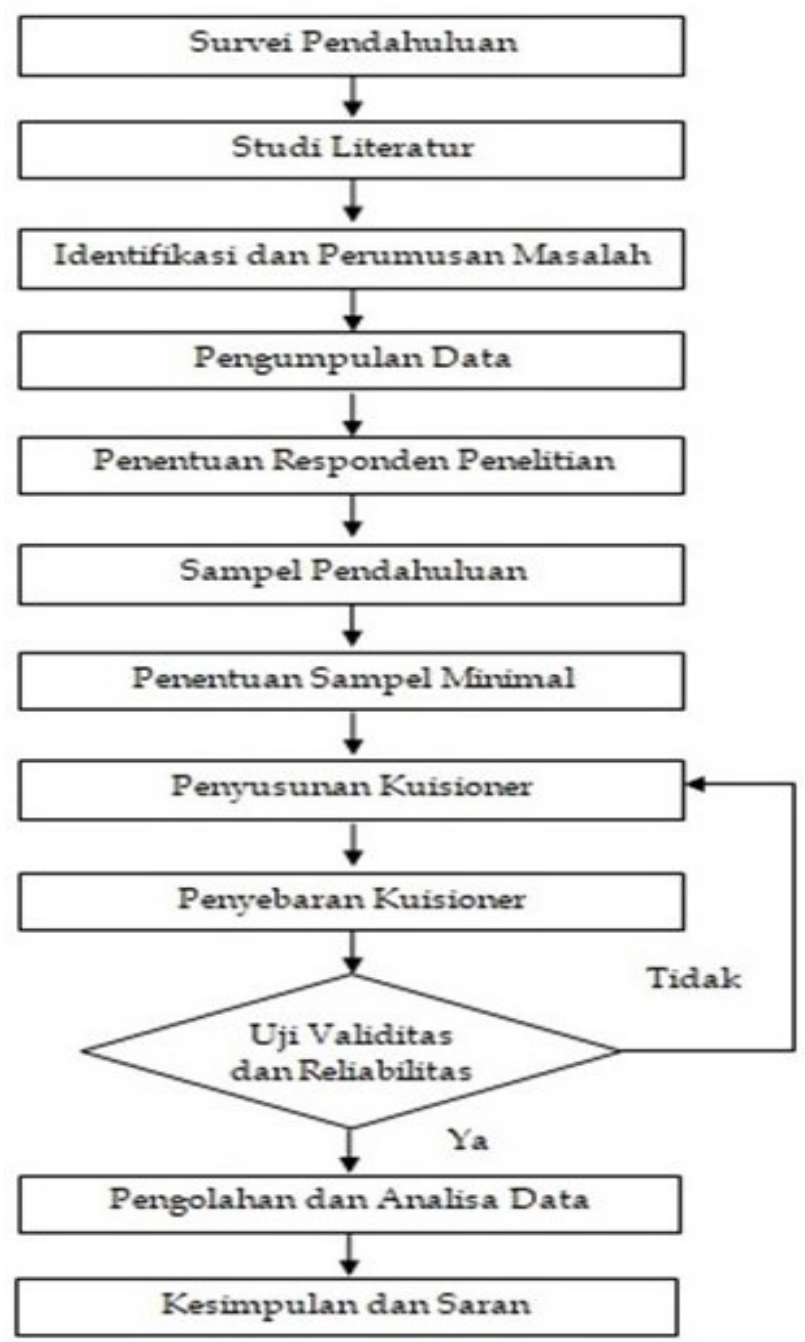

Gambar 1. Tahapan penelitian

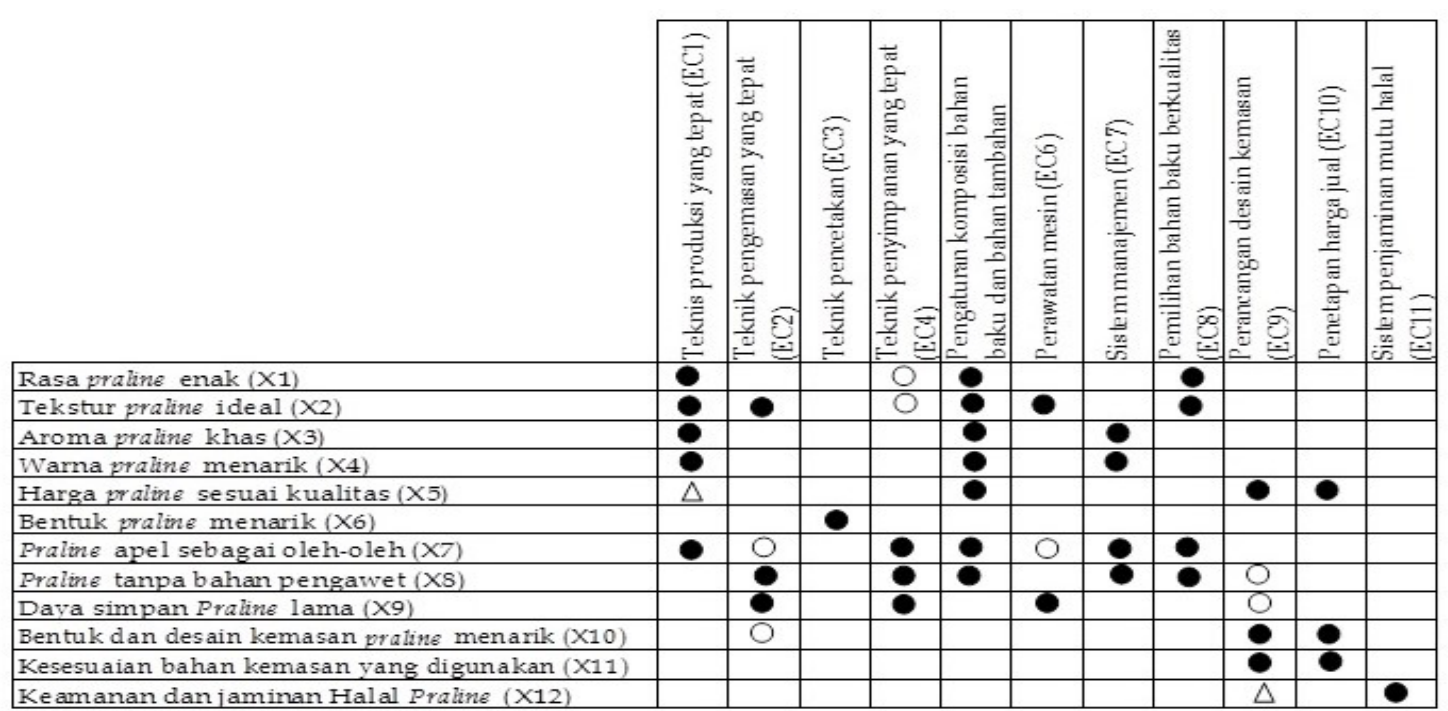

Gambar 2. Relationship matrix kebutuhan konsumen dan karakteristik teknis 


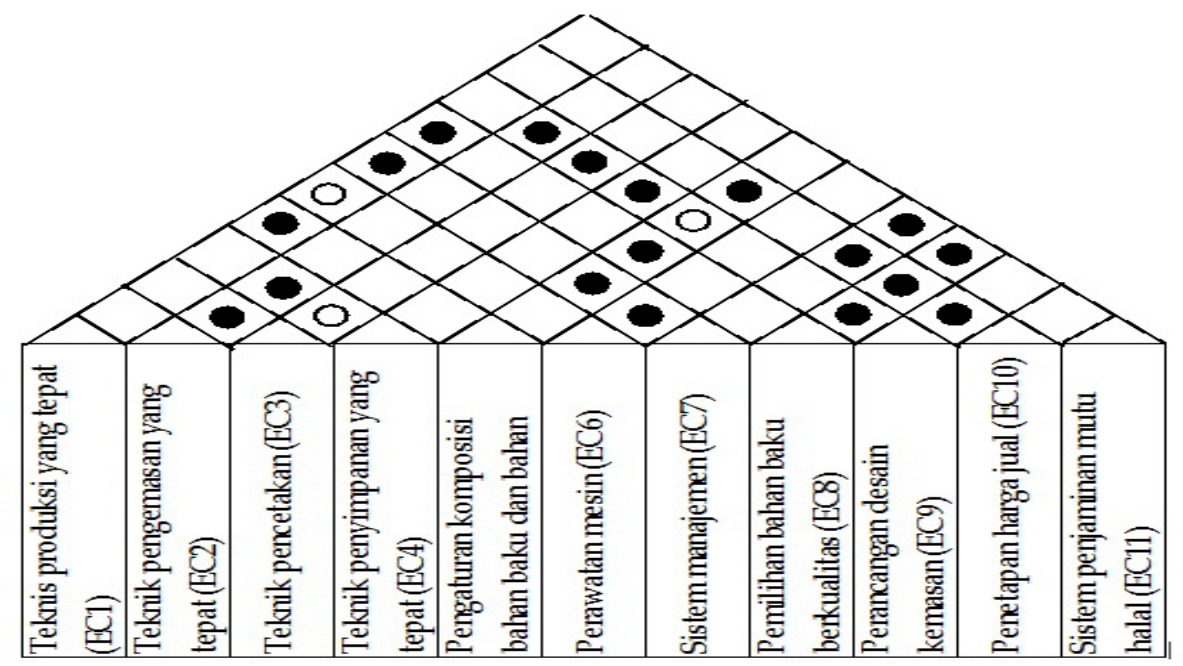

(a)

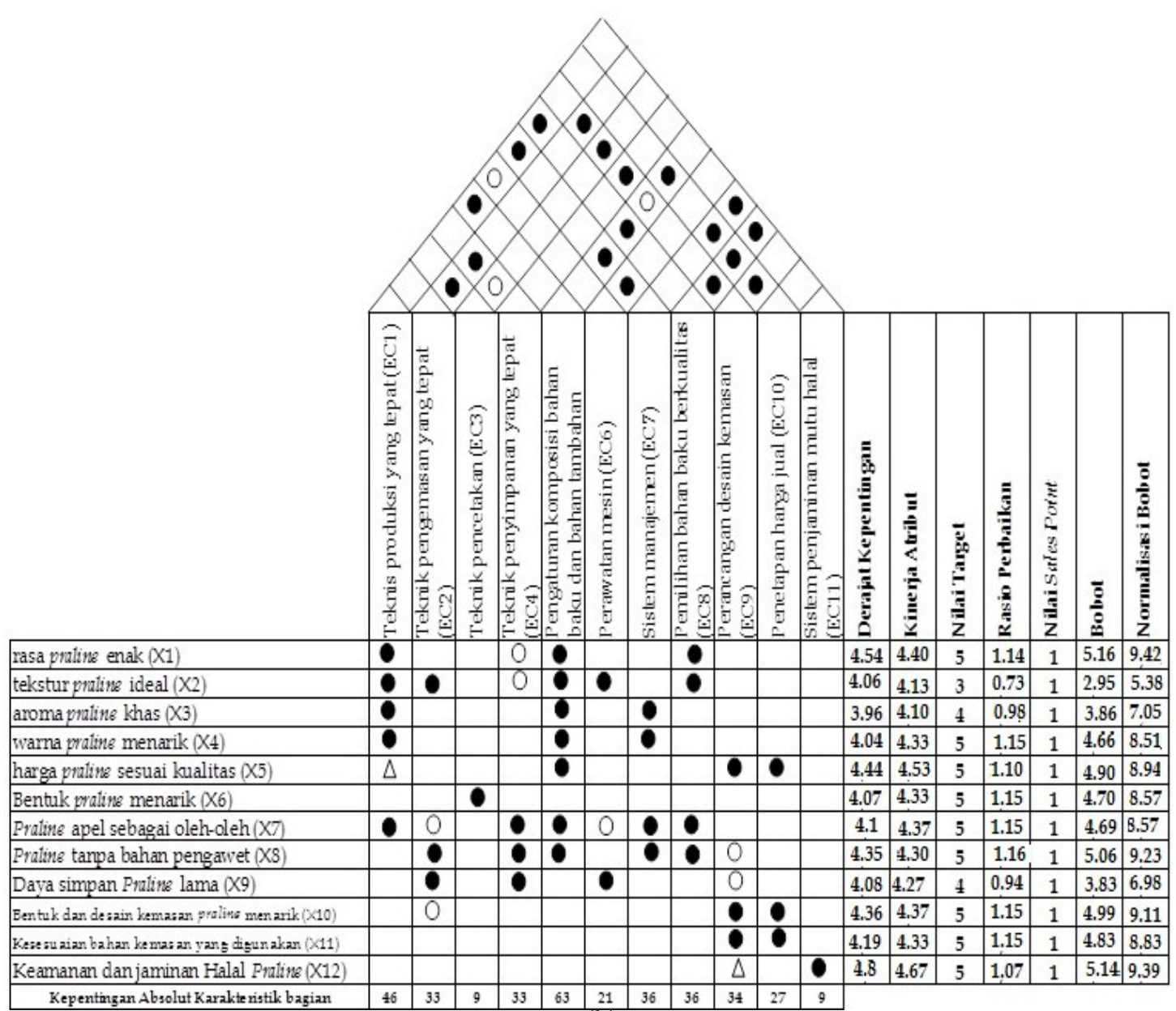

(b)

Gambar 3. (a) Correlation matrix antar karakteristik teknis praline apel (b) Matriks house of quality product planning praline apel 
Jurnal Teknologi Pertanian Vol. 20 No. 1 [April 2019] 1-10

Pengembangan Produk Praline Apel [Rohmah dkk]

dengan karakteristik teknis juga dicari bagaimana hubungan antar karakteristik teknis tersebut. Hasil penilaian terhadap hubungan antar karakteristik teknis produk praline dituangkan dalam matriks correlation yang dapat dilihat pada Gambar 3.

Secara umum hasil pengolahan data pada bagian product planning dapat dilihat pada Gambar 3. Pada Gambar 3 terdiri dari matriks korelasi di bagian atas (atap), matriks hubungan di bagian tengah, matriks pengembangan produk di bagian kanan dan matriks kepentingan absolut dan tingkat kepentingan relatif di bagian bawah.

\section{SIMPULAN}

Berdasarkan hasil analisis pengembangan produk menggunakan metode Quality Fuction Deployment (QFD) dapat diketahui bahwa produk praline apel memerlukan perbaikan atau pengembangan produk untuk dapat memenuhi kebutuhan konsumen. Perbaikan atau pengembangan produk praline apel dilakukan pada atribut keamanan dan jaminan halal dimana atribut ini merupakan atribut produk yang paling diinginkan atau diprioritaskan oleh konsumen yang harus dipenuhi dalam memproduksi praline apel.

\section{DAFTAR PUSTAKA}

Anggraeni, -M., Desrianty, -A., Yuniar. 2013. Rancangan meja dapur multifungsi menggunakan quality function deployment (QFD). Reka Integra - Jurnal Online Institut Teknologi Nasional. 2, 159-169. https://ejurnal.itenas.ac.id/index.php/ rekaintegra/article/view/231/487

Aqimudin, E, A., Kusmagi, M, A. 2010. Solusi Bila Terjerat Kasus Bisnis. Raih Asa Sukses

Diana. 2015. Penerapan metode e-servqual untuk evaluasi kualitas layanan sistem informasi. Jurnal Ilmiah Matrik. 17, 43-52. http://jurnal.binadarma.ac.id/index. $\mathrm{php} /$ jurnalmatrik/article/view/120/4

Direktorat Jenderal Industri Kecil dan Menengah Kementrian Perindustrian Republik Indonesia. 2011. One village one product (OVOP). Dilihat 12 Maret 2017. <http://ikm.kemenperin.go.id/ programmes/capacity-building/onevilage-one-product-ovop/>
Devani, -V., Kartikasari, D,-D., 2012. Usulan perbaikan kualitas pelayanan administrasi mahasiswa menggunakan metode quality function deployment (QFD). Jurnal Ilmiah Teknik Industri. 11, 185-197. https://doi.org/10.23917/jiti.v11i2.925

Ghazali, N,-H., 2016. A reliability and validity of an instrument to evaluate the school based assessment system : a pilot study. IJERE. 5, 148-157. https://files.eric.ed.gov/fulltext/ EJ1108537.pdf

Hidayat, A,-S., Siradj, -M. 2015. Sertifikasi halal dan sertifikasi non halal pada produk pangan industri. AHKAM. 15, 199-210. https://doi.org/10.15408/ajis.v15i2.2864

Jaiswal, E,-S., 2012. A case study on quality function deployment. IOSR Journal of Mechanical and Civil Engineering (IOSRJMCE). 3, 27-35. https://pdfs.semanticscholar.org/6423/e9a24e89e6176ef59c7775ab3129306559e8.pdf

Kosasih, -W., Soenandi, -I., Celsia, -E., 2013. Aplikasi QFD untuk pengembangan produk wafer (studi kasus PT Indo Sari Abadi). Jurnal Teknik dan Ilmu Komputer. 2, 258269. http://ejournal.ukrida.ac.id/ojs/ index.php/TIK/article/view/800/765

Moeljaningsih. 2011. PengaruhPenambahan Lesitin Terhadap Kualitas Permen Coklat Selama Penyimpanan Suhu Kamar. Reka Pangan. 4, 1-10.http://id.portalgaruda.org/?ref=brow se\&mod=viewarticle\&article $=180954$

Putra, Z,F,-S., Sholeh, -M., Widyastuti, -N., 2014. Analisis kualitas layanan website BTKPDIY menggunakan metode webqual 4.0. JARKOM. 1. https://journal.akprind. ac.id/index.php/script/article/view/335

Rangkuti, S, S., 2013. Umur simpan soyghurt probiotik sebagai filler coklat praline. Skripsi. UNRI. Riau

Sugiyono. 2012 Metode Penelitian Bisnis. Alfabeta. Bandung Suryaningrat, I,-B., Djumarti, Ruriani, -E., Kurniawati,-I., 2010. Aplikasi metode quality function deployment (QFD) untuk peningkatan kualitas produk mie jagung. Jurnal Agroteknologi. 4, 8-17. https://jurnal.unej.ac.id/ index.php/JAGT/article/view/2309

Triyono, -G., 2011. Pertimbangan melakukan denormalisasi pada model basis data relasi. Jurnal TELEMATIKA MKOM. 3, 19-25. http:/ / pascasarjana.budiluhur. ac.id/wp-content/uploads/2013/02/ Gandung_TM_Vol3No2.pdf

Zagloel, T, Y, M., Nurcahyo, R., 2013. TQM: manajemen kualitas total dalam perspektif teknik industri. Indeks. Jakarta 